\title{
In-Situ Temperature Dependent Raman Spectra of Coal
}

\author{
Ying-Fang XIE ${ }^{1, a}$, Jing-Lin YOU ${ }^{1, b *}$, Li-Ming LU ${ }^{2, c}$ \\ ${ }^{1}$ State Key Laboratory of Advanced Special Steel \& Shanghai Key Laboratory of advanced \\ Ferrometallurgy \&School of Materials Science and Engineering, Shanghai University, Shanghai \\ 200072, China \\ ${ }^{2}$ CSIRO Process Science and Engineering, Kenmore Qld 4069, Australia \\ ayingfangxie@163.com, bjlyou@163.com, 'lu_liming@hotmail.com \\ ${ }^{*}$ Corresponding author
}

Keywords: Coal, Raman Spectroscopy, Deconvolution, In-Situ High Temperature.

\begin{abstract}
This paper studied room temperature and in-situ high temperature Raman spectra of coal samples of different carbon content with $355 \mathrm{~nm}$ laser Raman spectrometer. The deconvoluted parameters of $\mathrm{D}$ band and $\mathrm{G}$ band were analysed. The relationship between different carbon content and the Raman spectra characteristics of different kinds of coals and the carbon content was studied. In-situ high temperature (from 298 to $1473 \mathrm{~K}$ ) Raman spectra of coals was tested. The change of internal structure during pyrolysis of coals was analysed and studied. Change of $\mathrm{G}$ band was discussed with the increase of temperature.
\end{abstract}

\section{Introduction}

Coal is an important energy source. As irreplaceable energy sources, coal can be widely used[1]. Coal has a very complicated structure due to different forming natural conditions. Usually, study on the structure of coal is divided into chemical and physical structure research[2]. Chemical research methods of coal included hydrogenation, oxidation, functional analysis and so on. Physical research methods of coal was the use of modern new technology and advanced equipment to carry on the research of coal structure, such as X-ray diffraction analysis, Infrared spectrum analysis, and so on.

Raman spectroscopy[3] is a molecular spectroscopy in recent years as a rapid development of micro analysis techniques. As a classical experimental tool of microstructure analysis, Raman spectroscopy[4] has becoming an advanced method. Since the 1970s, Raman spectroscopy has been used to study carbon materials, such as graphite, coal and so on. Green and coworkers[5] studied the structure of coal minerals. Tuinstra and Koenig[6], Friedel and Carlson[7] published the first Raman spectra of coal and reported $G$ peak and D peak through extensive studies. Johnson and Thomas[8] found that different grades of coal[9] as the temperature increases in the D band width decreases continuously. Benny-Bassez and Rouzaud[10] found that different levels of natural coal G+D' peak decreased with increasing coal rank, but they didn't find out such reduced regularity. Angoni[11] extracted different samples from graphite, coke, coal and anthracite to determine the difference between the Raman spectroscopy of different carbon content. He found that the width of $\mathrm{D}$ band was relevant to its irregular degree, but both D and G couldn't explain the irregular degree. Chunzhu Li and his collaborators ${ }_{[12]}$ analysed the pyrolysis and gasification of Australian brown coal by Raman spectroscopy, they deconvoluted Raman spectrum of coal from 800 to $1800 \mathrm{~cm}^{-1}$ to 10 characteristics spectrums successfully to reflect the highly disordered carbon materials and pointed out the sodium ions affect the pyrolysis of lignite in the coking reaction. Sheng[13] and his collaborators studied coal burning activity and micro structure during temperature of 1183-1773 K by Raman spectroscopy to explain the relationship between microstructure and combustion reactivity of chars[14].

The in-situ response experiment device can test the molecular chemical changes in the reaction conditions. It was reported that the changes of chemical bonds by in-situ infrared spectroscopy[15] study of coal pyrolysis. In-situ Raman spectroscopy has been widely used in many fields. This paper carries out an experimental research for in-situ temperature dependent Raman spectra of coals 
and analyses the internal structure characteristics of coal combined with the peak deconvolution.

\section{Experimental}

\section{Experimental Equipment}

The experimental Raman equipment was LabRam800HR of Horiba Jobin Y'von and achieved the in-situ high temperature dependent Raman spectroscopy by Linkam Heating Stage 1500 heating stage. Constant temperature precision was $\pm 1 \mathrm{~K}$ and temperature was determined by the thermocouple calibrated. Measurements were carried out by the $355 \mathrm{~nm}$ line and laser light source adopted ultraviolet pulse laser. The laser power was $0.2 \mathrm{~W}$ and scanning range was $200-2200 \mathrm{~cm}^{-1}$. The microscope objective was $4 \mathrm{x}$ with long focus distance.

\section{Experimental Samples and Method}

In Tab. 1, it was showed the contents of element $\mathrm{C}, \mathrm{H}$ and $\mathrm{N}$ of coal samples, which were tested by Elementar vario ELIII (Germany).

Tab. 1 Chemical composition of coal samples

\begin{tabular}{cccc}
\hline No. & $\mathrm{N}(\%)$ & $\mathrm{C}(\%)$ & $\mathrm{H}(\%)$ \\
\hline C1 & 1.84 & 79.69 & 4.67 \\
$\mathrm{C} 2$ & 1.92 & 77.84 & 4.72 \\
$\mathrm{C} 3$ & 1.81 & 78.56 & 4.5 \\
$\mathrm{C} 4$ & 1.88 & 78.54 & 4.26 \\
$\mathrm{C} 5$ & 2.12 & 76.63 & 5.36 \\
C6 & 1.84 & 77.02 & 4.62 \\
\hline
\end{tabular}

\section{Results and Discussion}

\section{Peak Deconvolution}

All Raman spectrums were recorded in room temperature by $355 \mathrm{~nm}$ ultraviolet excitation light from a solid semiconductor laser. The Raman spectra of all samples in room temperature were similar, Fig. 1 showed the Raman spectra of $\mathrm{C} 4$ in room temperature. Each Raman spectra was deconvoluted to two main peaks by Origin 8.0. One was assigned to $\mathrm{D}$ band and the other one $\mathrm{G}$ band. $\mathrm{D}$ band was around $1360 \mathrm{~cm}^{-1}$ which is disorder, defect, diamond band or $\mathrm{sp}^{3}$ hybridization carbon and $\mathrm{G}$ band was around $1580 \mathrm{~cm}^{-1}$ which is the graphite, tangential band or $\mathrm{sp}^{2}$ hybridization for carbonaceous materials[16]. Deconvolution could offer the wavenumber positions, width or FWHM (Full Width at Half Maximum) and relative intensity (peak or band area) of each peak.

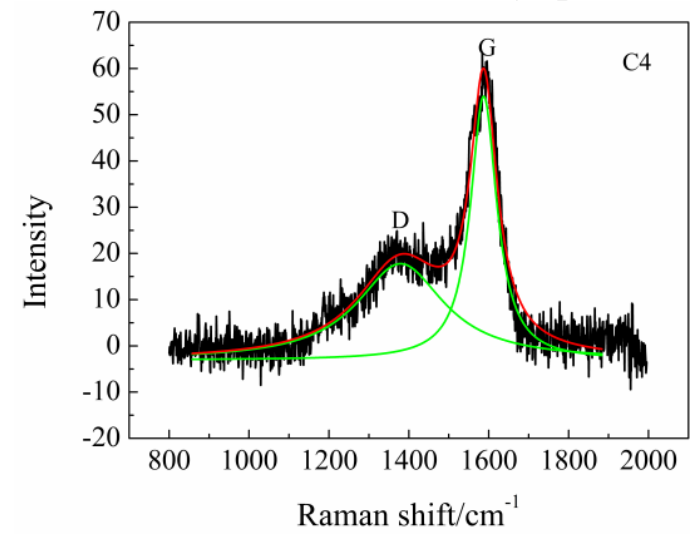

Fig. 1 Raman shift of sample C4

Compared with carbonaceous materials or organic components, inorganic materials such as 
alumino-silicates, behaved more sensitive and had higher cross section in the spectral instrumentation using $355 \mathrm{~nm}$ excitation laser. It collects relative external and surface structure information by using shorter wavenumber laser. It was estimated that the penetration depth was about several $100 \mathrm{~nm}$ for the laser of $355 \mathrm{~nm}$. There was more graphite in the surface of coal grain. It might imply the graphitization of coal in nature would happen from outside the coal grain to its center.

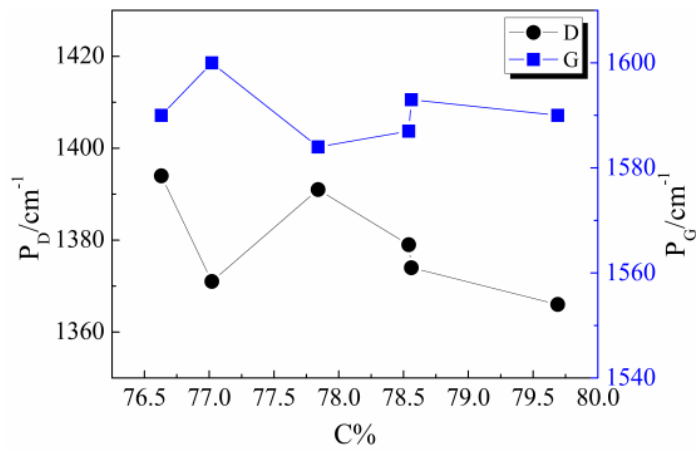

Fig. 2 Relationship of position of deconvoluted D band and G band with carbon content

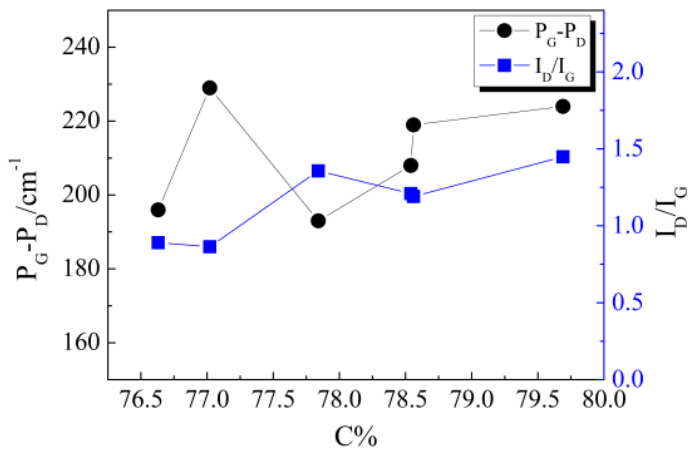

Fig. 3 Relationship of deconvoluted peak position difference $P_{G}-P_{D} \& I_{D} / I_{G}$ with carbon content

And deconvoluted parameters (such as $\mathrm{P}_{\mathrm{G}}-\mathrm{P}_{\mathrm{D}}, \mathrm{I}_{\mathrm{D}} / \mathrm{I}_{\mathrm{G}}, \mathrm{W}_{\mathrm{D}}, \mathrm{W}_{\mathrm{G}}$ ) were introduced to explain the relationships.

Fig. 2 showed the relationship of position of deconvoluted D band\& $\mathrm{G}$ band with carbon content. In fig. 2, when carbon content was less than $78 \%$ the intensity of $\mathrm{D}$ band decreased with the increasing of carbon content firstly and then increased. When carbon content was higher than $78 \%$, the intensity of D band decresed slowly.

However, G band showed opposite to D band. It may be concluded that slight change of carbon content may have the same effect on D band and G band.

Fig. 3 showed the relationship of deconvoluted peak position difference $P_{G}-P_{D} \& I_{D} / I_{G}$ with carbon content. $\mathrm{I}_{\mathrm{D}} / \mathrm{I}_{\mathrm{G}}$ meant the area ratio of $\mathrm{D}$ and $\mathrm{G}$ band. $\mathrm{P}_{\mathrm{G}}-\mathrm{P}_{\mathrm{D}}$ presented the gap of intensity of $\mathrm{G}$ band and $\mathrm{D}$ band. Fig. 8 showed that $\mathrm{P}_{\mathrm{G}}-\mathrm{P}_{\mathrm{D}}$ increased in principle with carbon content increasing. But $\mathrm{I}_{\mathrm{D}} / \mathrm{I}_{\mathrm{G}}$ increased firstly and then decreased with the increasing of carbon content when carbon content was less than $78 \%$. $\mathrm{I}_{\mathrm{D}} / \mathrm{I}_{\mathrm{G}}$ increased slowly with the increasing of carbon content when carbon content was higher than 78\%. It further verified the conclusion of Fig. 2. 


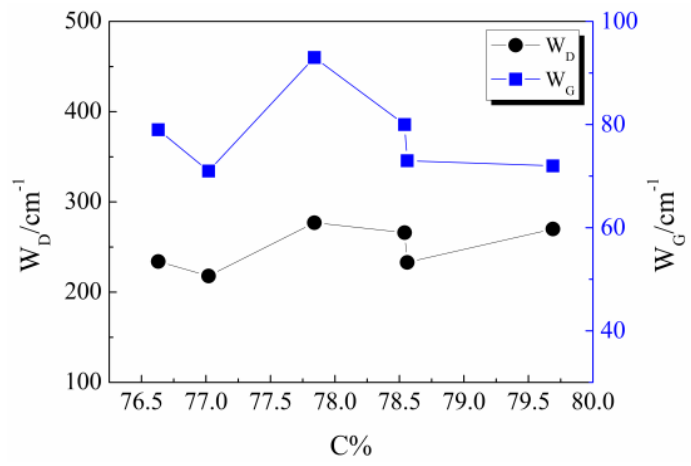

Fig. 4 Relationship of the width (FWHM) of deconvoluted G\& D band with carbon content

Fig. 4 showed the relationship of the width (FWHM) of deconvoluted G band and D band with carbon content. $\mathrm{W}_{\mathrm{D}}$ meant the FWHM of the deconvoluted D band, which was cooperated with the disordered and defect carbon. Meanwhile, $\mathrm{W}_{\mathrm{G}}$ represented the FWHM of the deconvoluted $\mathrm{G}$ band, which was related with the degree of graphitization of carbonaceous materials.

Fig. 4 showed $\mathrm{W}_{\mathrm{G}}$ decreased firstly and then increased when carbon content was less than $78 \%$. But when carbon content was higher than $78 \%, \mathrm{~W}_{\mathrm{G}}$ decreased slowly. And $\mathrm{W}_{\mathrm{D}}$ showed the same tendency compared to $\mathrm{W}_{\mathrm{G}}$. Combined Fig. 3 and Fig.4, it could conclude that $78 \%$ was the critical point of carbon content. When carbon content was less than $78 \%$, the disorder $\mathrm{sp}^{3}$ carbon species increased which brought the vibrational wavenumber of $\mathrm{D}$ band to increase. While carbon content was higher than $78 \%, \mathrm{sp}^{2}$ increased on the contrary, which implied that relative area of $\mathrm{G}$ band appeared to increase.

It should be mentioned[17] that the whole process is accompanied by the volatilization and decomposition of the organics. $\mathrm{W}_{\mathrm{G}}$ decreased slowly because of its stable graphite. Relative density of $\mathrm{sp}^{3}$ bondings in small molecules increased while the low-carbon organics precipitating, most $\mathrm{sp}^{3}$ bondings in low-carbon organics emerged as unified species as a prominent contribution to the decreasing of the $\mathrm{W}_{\mathrm{D}}$ when carbon content was higher than $78 \%$. It meant that the spectrum contained more information of low-carbon organics instead of the remaining coal.

\section{In-Situ High Temperature Results and Discussion}

Fig. 5 showed the in-situ temperature dependent Raman spectra[18] of $\mathrm{C} 1$ in Ar atmosphere. Ar gas flow rate was controlled by bubbles test in water, about 160 bubbles per minute. When the temperature was lower than $473 \mathrm{~K}$, the heating rate was $30 \mathrm{~K}$ per min. When the temperature was higher than $473 \mathrm{~K}$, the heating rate was $50 \mathrm{~K}$ per min. When the temperature was lower than $873 \mathrm{~K}$, the integral time and frequency was $20 \times 20$. When the temperature was higher than $873 \mathrm{~K}$, the integral time and frequency was 30x30. Yellow substance was observed in the temperature of $673 \mathrm{~K}$. This yellow substance was tar oil by analysis[19]. The spectrum labeled as $873 \mathrm{~K}-2$ was the second determination after 40 minutes pyrolysis at $873 \mathrm{~K}$ and cleaning the optical silica glass at room temperature followed re-heating back to $873 \mathrm{~K}$. All cooling rate was $50 \mathrm{~K}$ per minute.

Fig. 6 showed that the in-situ temperature dependent Raman spectra of C4 in Ar atmosphere. The integral time and frequency was 30x30 in the heating process. The experimental conditions of C3, C4, C5 and C6 were as the same as that of C4.

From all the in-situ temperature dependent Raman spectra of all samples, it could be observed that $\mathrm{D}$ band was decreasing with the increase of temperature. It implied that graphitization degree became higher with the increase of temperature.

In the same time, a sharp peak could be observed at around $1559 \mathrm{~cm}^{-1}$ in nearly all the individual spectrum at different temperature. This sharp peak which was a plasma line could help to find out the variation of the $G$ peak position with the increase of temperature clearly. G peak position would shift blue and the intensity would become weaker with the increase of temperature due to the decreasing volatile contents in the samples. It demonstrated that $\mathrm{G}$ peak position was effected by the volatile occupying and adsorption on the surface of coal. 


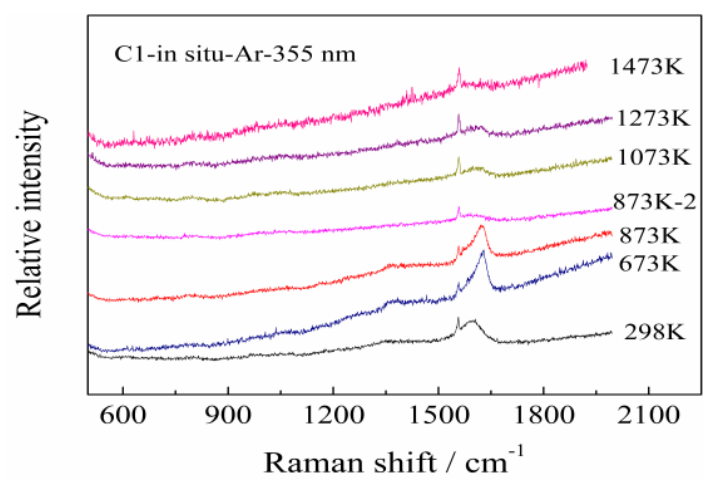

Fig. 5 In-situ temperature dependent Raman spectra of C1 in Ar atmosphere

The spectrum of C2, C3 and C6 showed the same phenomenon as that of C4 at $673 \mathrm{~K}$. The spectrum at $673 \mathrm{~K}$ seemed strange and unique, which was quite different to all other spectrums. It implied that the liquid substance had emerged on the surface of coal because of the extension of

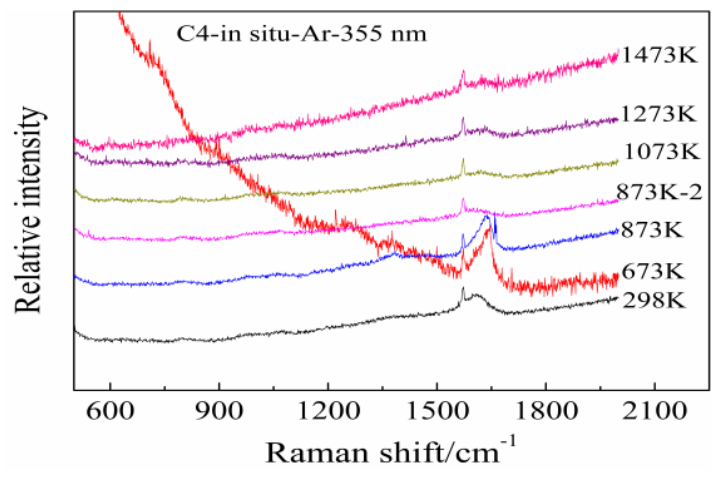

Fig. 6 In-situ temperature dependent Raman spectra of C4 in Ar atmosphere

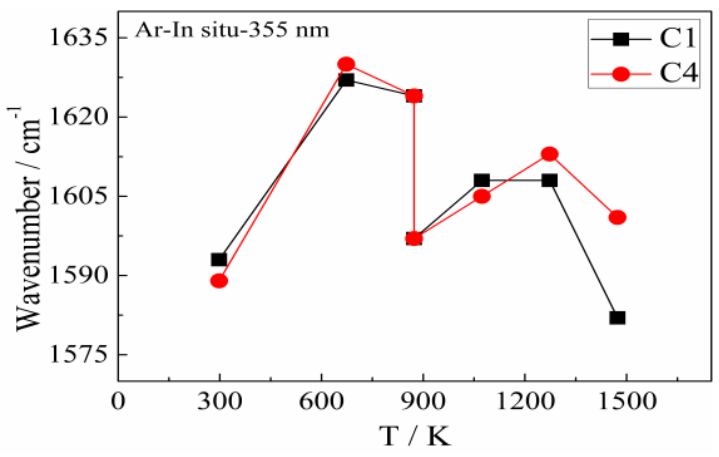

Fig. 7 In-situ temperature dependent peak position of $\mathrm{G}$ band for $\mathrm{C} 1$ and $\mathrm{C} 4$ pyrolysis in $\mathrm{Ar}$ atmosphere

Rayleigh line[20]. When the temperature exceeded the curing temperature $873 \mathrm{~K}$, it might appear adhesion phenomena and form to char. It showed in-situ temperature dependent peak position variations of $\mathrm{G}$ band for $\mathrm{C} 1$ and $\mathrm{C} 4$ pyrolysis in Ar atmosphere in figure 7. By the experimental observation and $\mathrm{G}$ band peak position variations of coals, it could be concluded that low-carbon organics precipitate considerably and begin to volatilize at the temperature of $673 \mathrm{~K}$, and some of them would stay on the surface of coal grain as liquid state. There was also a critical point at the temperature of $873 \mathrm{~K}[21]$. When the temperature was higher than $873 \mathrm{~K}$, most high-carbon organics would start precipitating and volatilizing. At the same time, the peak positions of $\mathrm{G}$ band at $1073 \mathrm{~K}$ and $1273 \mathrm{~K}$ were also larger than that of second value at $873 \mathrm{~K}$. It proved that most high-carbon organics precipitate and volatilize from inside to surface of the coal from $873 \mathrm{~K}$ to $1273 \mathrm{~K}$ and 
mostly decompose at $1473 \mathrm{~K}$ rapidly. Meanwhile, it was observed that C2, C3, C5 and C6 behaved as the same as $\mathrm{C} 1$ and $\mathrm{C} 4$.

\section{Summary}

In room temperature, $78 \%$ was the critical point of carbon content. When carbon content was less than $78 \%$, the disorder $\mathrm{sp}^{3}$ carbon species increased which resulted in the vibrational wavenumber of $\mathrm{D}$ band to increase. While carbon content was higher than $78 \%, \mathrm{sp}^{2}$ increased on the contrary.

In-situ high temperature dependent experiment, the sharp peak around $1559 \mathrm{~cm}^{-1}$ which was a plasma line could help to find out the variation of the $G$ peak position with the increase of temperature clearly. G peak position would shift blue and the intensity would become weaker with the increase of temperature due to the decreasing volatile contents in the samples. Peak position variations of $\mathrm{G}$ band could help to conclude that low-carbon organics precipitate considerably and begin to volatilize at $673 \mathrm{~K}$ and some of them would stay on the surface of coal as liquid due to the extension of Rayleigh line. The temperature at $873 \mathrm{~K}$ was a critical temperature.

\section{Acknowledgments}

This work was supported by the key project of Chinese National Natural Science Funds (50932005), Chinese National Natural Science Funds (20973107 \& 40973046), the Shanghai Committee of Science and Technology and CSIRO Minerals Down Under Flagship of Australia. You Jing-lin e-mail address: jlyou@staff.shu.edu.cn

\section{References}

[1] Y.Z. Yongjin, and Shanying Hu, Journal of chemical industry and Engineering, 63 (2012) 3-8.

[2] J. Chen, Shandong chemical industry, 34 (2005) 23-25.

[3] Z.B.Y.Y.L.L.e. al, Clean Coal Technology, 21 (2015) 79-82.

[4] N.M. S. Potgieter-Vermaak, N. Wagner, et al, Journal of Raman Spectroscopy, 42 (2011) 123-129.

[5] P.D. Green, C.A. Johnson, K.M. Thomas, Fuel, 62 (1983) 1013-1023.

[6] F. Tuinstra, J.L. Koenig, The Journal of Chemical Physics, 53 (1970) 1126-1130.

[7] R.A. Friedel, G.L. Carlson, Fuel, 51 (1972) 194-198.

[8] C.A. Johnson, J.W. Patrick, K. Mark Thomas, Fuel, 65 (1986) 1284-1290.

[9] R. Hinrichs, M.T. Brown, M.A.Z. Vasconcellos, M.V. Abrashev, W. Kalkreuth, International Journal of Coal Geology, 136 (2014) 52-58.

[10] J.N. Rouzaud, A. Oberlin, C. Beny-Bassez, Thin Solid Films, 105 (1983) 75-96.

[11]K. Angoni, Carbon, 31 (1993) 537-547.

[12] C.L. Xiaojiang Li, Journal of Fuel Chemistry and Technology, 33 (2005) 385-390.

[13]C. Sheng, Fuel, 86 (2007) 2316-2324.

[14]X. Liu, Y. Zheng, Z. Liu, H. Ding, X. Huang, C. Zheng, Fuel, 157 (2015) 97-106.

[15]X. Qi, D. Wang, H. Xin, G. Qi, Energy \& Fuels, 27 (2013) 3130-3136.

[16] A. Tselev, I.N. Ivanov, N.V. Lavrik, A. Belianinov, S. Jesse, J.P. Mathews, G.D. Mitchell, S.V. Kalinin, Fuel, 126 (2014) 32-37.

[17]L. Liu, Y. Cao, Q. Liu, Fuel, 146 (2015) 103-110. 
[18] YOU Jing-lin, JIANG Guo-chang, ZHOU Dong-ming, et al. Chinese Journal. of light scattering, 17 (2005) 4-6.

[19] Y.J. YU Liwang, WANG Yuanyuan, et al, Journal of Fuel Chemistry and Technology, 43 (2015).

[20]G.-C.J. J.-L. You, H.-Y. Hou, et al JOURNAL OF RAMAN SPECTROSCOPY, 36 (2005) 237-249.

[21] Y.J. Liu Xiaofei, Wang Yuanyuan, et al, Journal of Fuel Chemistry and Technology, 42 (2014) 270-276. 